\title{
Thermal Aging of HTPB/IPDI-based Polyurethane as a Function of NCO/OH Ratio
}

\author{
Luciene Dias Villar ${ }^{\mathrm{a}, *}$, Thiago Cicaglioni ${ }^{\mathrm{b}}$, Milton Faria Diniz ${ }^{\mathrm{a}}$, \\ Marta Ferreira Koyama Takahashi, Luis Cláudio Rezende ${ }^{\mathrm{a}}$ \\ ${ }^{a}$ Divisão de Química, Instituto de Aeronáutica e Espaço, \\ Departamento de Ciência e Tecnologia Aeroespacial - DCTA, \\ Praça Marechal do Ar Eduardo Gomes, 50, São José dos Campos, SP, Brazil \\ ${ }^{b}$ Departamento de Engenharia Química, Escola da Engenharia de Lorena, \\ Universidade de São Paulo, CP 116, Lorena, SP, Brazil
}

Received: March 16, 2011; Revised: July 8, 2011

\begin{abstract}
Thermal aging of hydroxy-terminated polybutadiene/isophorone diisocyanate (HTPB/IPDI)-based polyurethane was studied as a function of $\mathrm{NCO} / \mathrm{OH}$ ratio (1.0 and 0.85). Samples were aged in air ovens at 50, 60,65 , and $70{ }^{\circ} \mathrm{C}$ for periods of time from 1 to 34 weeks. Changes in chemical (swelling testing and FT-IR spectroscopy) and mechanical (tension testing and hardness) properties were evaluated throughout the aging assays. Correlation between equilibrium swelling ratio and elastic modulus, coupled with changes in FT-IR spectra, indicated oxidative cross-linking as the dominant mechanism for both molar ratios investigated. However, determination of Arrhenius activation energy resulted in values of $(82 \pm 10) \mathrm{kJ} \mathrm{mol}^{-1}$ and $(156 \pm 30) \mathrm{kJ} \cdot \mathrm{mol}^{-1}$ for 1.0 and $0.85 \mathrm{NCO} / \mathrm{OH}$ ratios, respectively, thus revealing faster oxidative degradation kinetics for higher urethane linkage networks.
\end{abstract}

Keywords: aging, $H T P B$, polyurethane

\section{Introduction}

Hydroxy-terminated polybutadiene (HTPB)-based polyurethanes are used in a wide range of applications, from sealants and coating materials to binders of solid rocket propellants. Propellant binders are obtained by cross-linking the terminal hydroxyl groups $(\mathrm{OH})$ of HTPB prepolymer with di- or polyfunctional isocyanates (NCO), thus resulting in an elastomeric network, which can withstand the stress loading variations occurring from storage to ignition and flight ${ }^{1}$.

Nevertheless, due to the unsaturated character of the repeated unit, polybutadiene is well-known to be sensitive to oxidation, even in the presence of stabilizers ${ }^{2}$, thus resulting in hardening and embrittlement of HTPB-based polyurethanes, which are attributed to the cross-linkage through the double bonds of polybutadiene ${ }^{3}$. Therefore, depending on the environmental conditions, changes on mechanical properties of propellant binders may compromise the structural integrity of solid rockets, leading to service life constraints ${ }^{4}$.

Since the service life of rockets are largely dependent on the behavior of mechanical properties during aging, a formulation parameter such as $\mathrm{NCO} / \mathrm{OH}$ ratio, which undoubtfully affects the mechanical properties ${ }^{5,6}$, may also affect the aging behavior of solid propellant binders and, by doing so, the reliability of rocket systems. A study ${ }^{7}$ carried out for aging of sixteen HTPB/IPDI-composite propellants has found out that changes were faster when formulations were prepared with higher $\mathrm{NCO} / \mathrm{OH}$ and triol/diol ratios. However, the remarks from this study are limited, once they have worked with a very narrow range of molar ratio (from 0.81 to 0.85 ).

This work analyzes the effect of $\mathrm{NCO} / \mathrm{OH}$ molar ratio (1.0 and 0.85 ) on the aging behavior of chemical (swelling testing and FT-IR spectroscopy) and mechanical (tension testing and hardness) properties of HTPB/IPDI-based polyurethanes.

\section{Materials and Methods}

\subsection{HTPB/IPDI-based polyurethane}

The polyurethane material was prepared from polymerization of HTPB (Petroflex S.A.) with IPDI (Veba Chemie A.G.) and addition of $0.012 \% \mathrm{w} / \mathrm{w}$ ferric acetylacetonate (Merck, Inc.) as catalyst. Sheets of $2 \mathrm{~mm}$ thickness were cast and cured for 1 week at $50{ }^{\circ} \mathrm{C}$. IPDI and HTPB were mixed into a 1.0 or $0.85 \mathrm{NCO} / \mathrm{OH}$ ratio, rendering $\mathrm{F} 1$ and $\mathrm{F} 2$ formulations, respectively.

\subsection{Thermal aging assays}

Thermal aging of the HTPB/IPDI-based elastomers were carried out in type IIB forced ventilation ovens (ASTM E145-94 (Reapproved 2006)) under atmospheric pressure and RH less than 20\%. Aging conditions were set up by following ASTM D3045-92 (Reapproved 2003) recommendations. The first assay was carried out at 50,60, and $70{ }^{\circ} \mathrm{C}$ having withdraws after $0,2,8,24$, and 34 weeks of storage. An additional assay was designed with shorter periods of aging time $(0,1,2,3,4,6$, and 8 weeks $)$ at 60 and $65^{\circ} \mathrm{C}$.

\subsection{Mechanical testing}

Dumbbell-shaped specimens were cut from the HTPB/IPDI $2 \mathrm{~mm}$-sheets and assayed for uniaxial tension tests, according to ASTM D412-06a in a Zwick 1474 testing machine at $(23 \pm 2){ }^{\circ} \mathrm{C}$ and a cross-head speed of $500 \mathrm{~mm} / \mathrm{min}$. Actual strain was measured with an optical extensometer. The initial modulus of elasticity (Young modulus) was defined as the secant modulus between 3 and $10 \%$ of elongation. Hardness was measured in circular specimens with $7 \mathrm{~mm}$ thickness by using Zwick Shore A tester according to ASTM D2240- 
05. All reported results of mechanical properties and hardness are averages of ten and five measured values, respectively.

\subsection{Swelling testing}

Swelling testing was performed gravimetrically ${ }^{8}$. Circular discs (10 $\mathrm{mm}$ in diameter, $2 \mathrm{~mm}$-thickness, 0.3 to $0.4 \mathrm{~g}$ ) were previously weighted and placed, in triplicate, into chloroform at room temperature until equilibrium was reached (7 days). The swollen sample disks were weighted $\left(w_{1}\right)$ and placed to dry up to constant mass $\left(w_{2}\right)$. Swelling ratio was calculated by following Equation $1^{[8]}$ :

$$
q_{v}=1+\frac{\rho_{2}}{\rho_{1}} \times\left(\frac{w_{2}-w_{1}}{w_{1}}\right)
$$

where, $q_{v}$ is the swelling ratio by volume, $\rho_{1}$ and $\rho_{2}$ are the densities at $25{ }^{\circ} \mathrm{C}$ of the solvent ( $\rho_{1}=1.47 \mathrm{~g} \cdot \mathrm{mL}^{-1}$ for chloroform) and of the polymer after swelling and drying, respectively. Density measurement of HTPB-elastomers relied on the Archimedes approach, by using the weight difference of an approximately $0.20 \mathrm{~g}$-sample weighted in air and in distilled water.

\subsection{FT-IR analysis}

Fourier transform infrared spectra (FT-IR) were collected by using a PerkinElmer Spectrum One spectrometer equipped with an Universal Attenuated Total Reflectance (UATR) and an Attenuated Total Reflectance (ATR/Ge/45 ${ }^{\circ}$ ) devices at: spectral range $4000-700 \mathrm{~cm}^{-1} ; 40$ scans and $4 \mathrm{~cm}^{-1}$ resolution. Samples aged at $70{ }^{\circ} \mathrm{C}$ were analyzed at surface and core regions. Surface analysis was made without any previous treatment of samples. Core region was examined by slicing of the samples throughout their thickness.

\section{Results and Discussion}

\subsection{Mechanical properties}

Tensile strength and elongation at break, elastic modulus and hardness of unaged HTPB/IPDI-based elastomers for both formulations investigated are presented in Table 1 . As it should be expected, the higher number of urethane linkages present in the binder prepared with stoichiometric $\mathrm{NCO} / \mathrm{OH}$ ratio resulted in a remarkable increase in hardness and modulus, and a decrease in elongation. A less pronounced difference was observed in tensile strength.

The behavior of elastic modulus during thermal aging of the HTPB/IPDI polyurethanes is showed in Figure 1. Solid and open symbols are for long- (up to 34 weeks) and short-term (up to 8 weeks) assays, respectively. Since the mechanical tension testing was unable to be carried out for samples showing severe embrittlement, the latter assay was planned to fulfill the data required to better establish the aging behavior.

A general trend of modulus increase could be observed for both formulations at all the temperatures tested (Figure 1). A correspondent decrease in tension strength and elongation at break was observed (data not shown), thus revealing a markedly tendency of polyurethane hardening. A severe embrittlement was observed for F1-samples aged at $70^{\circ} \mathrm{C}$ for times longer than 2 weeks, whereas F2-samples showed a greater resistance by withstanding a period of 8 weeks before embrittlement was observed.

Table 2 presents the aging constant rate $(k)$ obtained from the linear regression of elastic modulus and $\ln \left(\mathrm{t} / \mathrm{t}_{0}\right)$, as empirically proposed by Christiansen et al. ${ }^{9}$.

At temperatures from 50 to $65^{\circ} \mathrm{C}$, aging rates resulted higher for stoichiometric HTPB/IPDI-formulation, as indicated by the ratio $k_{\mathrm{F} 1} / k_{\mathrm{F} 2}$ (Table 2), meanwhile similar rates was observed at $70{ }^{\circ} \mathrm{C}$. In fact, the very few number of experimental data obtained at the higher aging temperature may have resulted in low accuracy of the calculated rates. In spite of that, the application of Arrhenius equation to determine the activation energy for HTPB-binder oxidation resulted in values of $(82 \pm 10) \mathrm{kJ} . \mathrm{moL}^{-1}$ and $(156 \pm 30) \mathrm{kJ} . \mathrm{moL}^{-1}$ for $\mathrm{NCO} / \mathrm{OH}$ ratios of 1.0 and 0.85 , respectively, with linear regression coefficients higher than 0.96 (data not shown).

The kinetic results presented herein indicate that the presence of a higher number of urethane linkages may accelerate the oxidation of HTPB-based polyurethanes. Although the present work was not able to point out any reasons for this finding, it is well known that a higher urethane group concentration lowers thermal stability of polyurethanes $^{10}$.
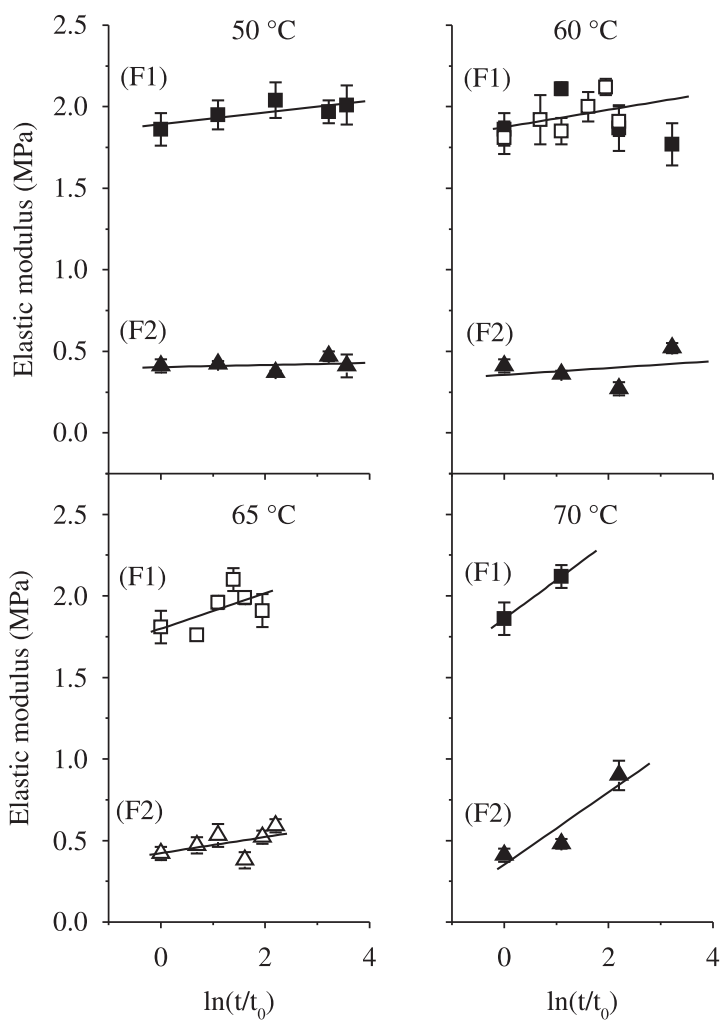

Figure 1. Modulus variation with aging time and $\mathrm{NCO} / \mathrm{OH}$ ratio. (F1): $\mathrm{NCO} /$ $\mathrm{OH}=1.0 ;(\mathrm{F} 2): \mathrm{NCO} / \mathrm{OH}=0.85$. Solid and open symbols are for long- and short-term assays, respectively.

Table 1. Mechanical properties of the unaged HTPB/IPDI-based elastomers.

\begin{tabular}{cccccc}
\hline $\begin{array}{c}\text { HTPB/IPDI-based } \\
\text { formulation }\end{array}$ & $\begin{array}{c}\mathrm{NCO} / \mathrm{OH} \\
\text { ratio }\end{array}$ & $\begin{array}{c}\text { Tensile strength at break } \\
(\mathrm{MPa})\end{array}$ & $\begin{array}{c}\text { Elongation at break } \\
(\%)\end{array}$ & $\begin{array}{c}\text { Elastic modulus } \\
(\mathrm{MPa})\end{array}$ & $\begin{array}{c}\text { Hardness } \\
(\mathrm{ShA})\end{array}$ \\
\hline F1 & 1.0 & $1.4 \pm 0.1$ & 260 & $1.8 \pm 0.1$ & $40 \pm 1$ \\
F2 & 0.85 & $1.1 \pm 0.1$ & 1200 & $0.42 \pm 0.04$ & $12 \pm 1$ \\
\hline
\end{tabular}


Table 2. Aging constant rate obtained from elastic modulus.

\begin{tabular}{cccccc}
\hline $\begin{array}{c}\text { HTPB/IPDI-based } \\
\text { formulation }\end{array}$ & $\begin{array}{c}\mathrm{NCO} / \mathrm{OH} \\
\text { ratio }\end{array}$ & $50{ }^{\circ} \mathrm{C}$ & $60{ }^{\circ} \mathrm{C}$ & \multicolumn{3}{c}{ Aging constant rate, $k \times \mathbf{1 0}^{-\mathbf{2}}(\mathbf{M P a})$} \\
\cline { 3 - 6 } $\mathrm{F} 1$ & 1.0 & 3.6 & 5.3 & 11 & 24 \\
$\mathrm{~F} 2$ & 0.85 & 0.64 & 2.1 & 5.0 & 22 \\
$k_{\mathrm{F} 1} / k_{\mathrm{F} 2}$ & - & 5.6 & 2.5 & 2.2 & 1.1 \\
\hline
\end{tabular}

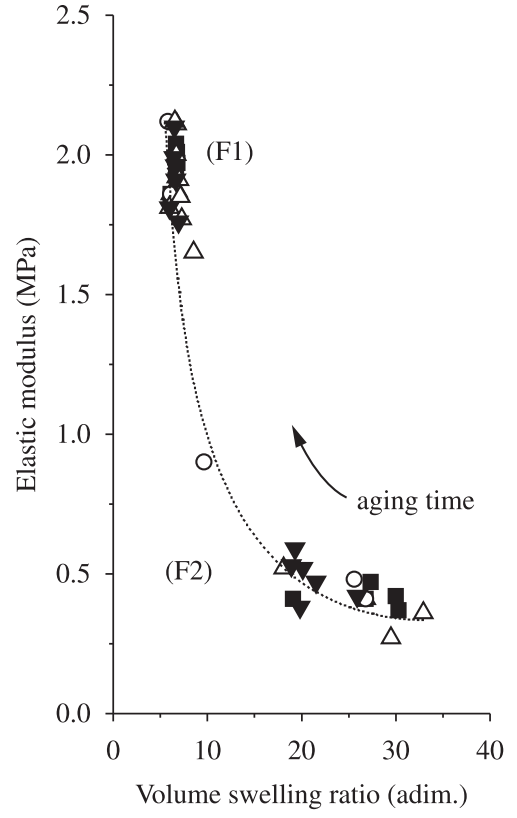

$50{ }^{\circ} \mathrm{C} \quad \triangle 60{ }^{\circ} \mathrm{C} \quad \nabla 65^{\circ} \mathrm{C} \quad \circ 70^{\circ} \mathrm{C}$

Figure 2. Correlation between elastic modulus and volume swelling ratio $(q v)$ for HTPB/IPDI-based elastomers. (F1): $\mathrm{NCO} / \mathrm{OH}=1.0$; $(\mathrm{F} 2)$ : $\mathrm{NCO} / \mathrm{OH}=0.85$

\subsection{Swelling ratio}

Determination of density for dried HTPB/IPDI-based elastomers after equilibrium swelling testing resulted in $\rho_{2}$ values of $(0.84 \pm 0.05)$ and $(0.90 \pm 0.01)$ g. $\mathrm{mL}^{-1}$ for $\mathrm{F} 1$ - and F2- formulations, respectively. The binder formulation prepared with the lower $\mathrm{NCO} / \mathrm{OH}$ ratio presented a volume swelling degree of $26.3 \pm 0.1$, against only $6.1 \pm 0.1$ for the other formulation, thus giving an indication of the great difference in cross-linking density between both elastomeric binders.

Figure 2 summarizes the changes in elastic modulus and equilibrium swelling ratio by volume for all the temperatures investigated during the aging assays. A noticeable exponential correlation between crosslinking increase and hardening of HTPB-binder can be observed, thus confirming cross-linkage as the main mechanism of degradation for the tested material. Such mechanism was present in both formulations, although by the correlation showed in Figure 2, at higher $\mathrm{NCO} / \mathrm{OH}$ ratio a small change in the swelling ratio may have a more pronounced effect on modulus, thus making the service life of the HTPB-binder to be shorter.

\subsection{FT-IR analysis}

Infrared spectra of HTPB/IPDI-based elastomers differing at $\mathrm{NCO} / \mathrm{OH}$ ratio are presented in Figure 3 for the following conditions: a) surface of unaged sample; b) surface of aged sample at $70{ }^{\circ} \mathrm{C}$ for
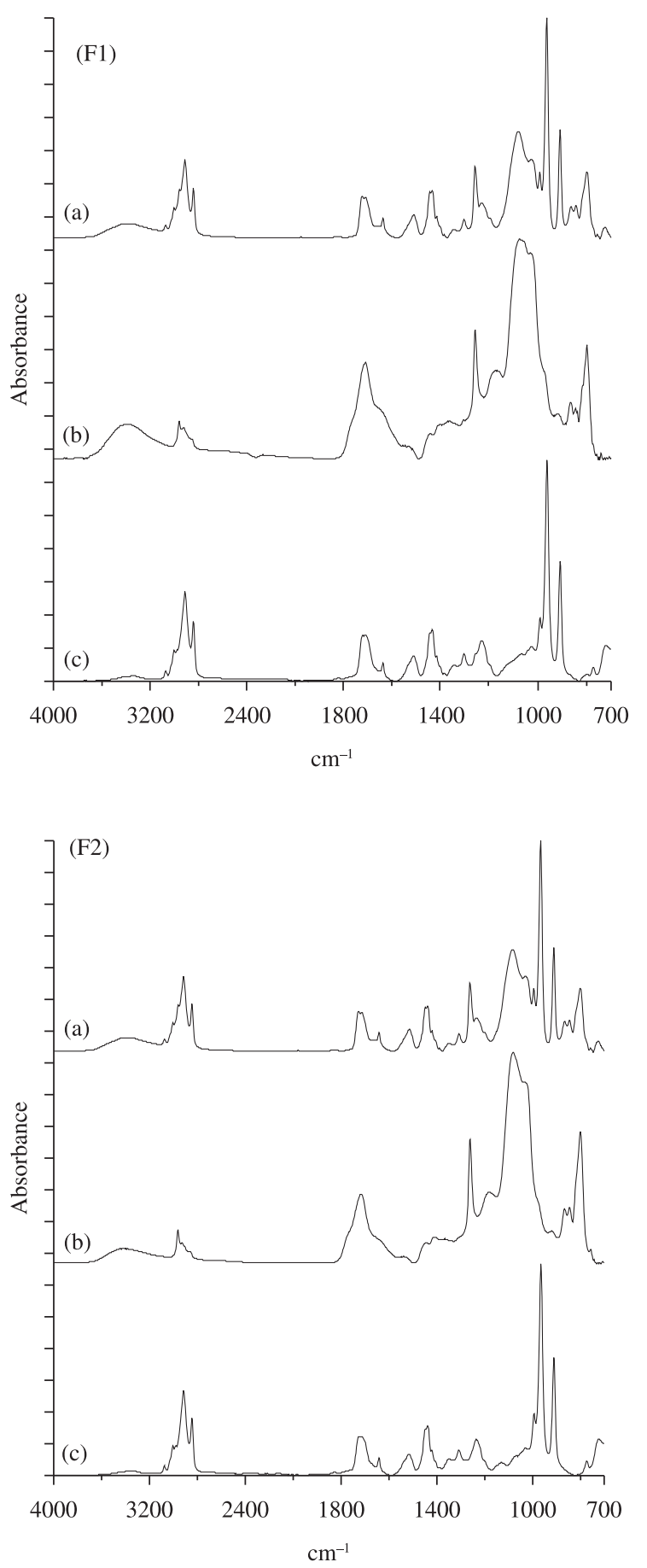

Figure 3. FT-IR spectra of HTPB/IPDI-based polyurethanes. (F1) NCO/ $\mathrm{OH}=1.0 ;(\mathrm{F} 2) \mathrm{NCO} / \mathrm{OH}=0.85$. a) surface of unaged sample; b) surface of aged sample at $70{ }^{\circ} \mathrm{C}$ for 8 weeks; and c) core region of aged sample at $70{ }^{\circ} \mathrm{C}$ for 8 weeks. 
8 weeks; and c) core region of aged sample at $70{ }^{\circ} \mathrm{C}$ for 8 weeks. Conditions (a) and (b) were examined by ATR $/ \mathrm{Ge} / 45^{\circ}$ device, meanwhile condition (c) was examined by UATR device, due to the breakage of Germanium crystal during the analysis performance. Vibrational modes were indicated as follows: $v$, for axial stretching; $\delta$, for angular deformation; and $\omega$, for wagging vibration.

Inspection of unaged spectra showed similar absorptions for both formulations (Figure 3a). Even the hydroxyl-free groups $(\mathrm{vOH})$, assigned in the $3350-3400 \mathrm{~cm}^{-1}$ region, and present in $\mathrm{F} 2$ due to excess amount of HTPB, were not possible to differentiate due to the presence of $\mathrm{NH}$ groups $(\mathrm{vNH})$, which absorb in the same region $\left(3357 \mathrm{~cm}^{-1}\right)$. It is worthwhile to mention that absorption bands at $1260 \mathrm{~cm}^{-1}\left(\delta \mathrm{SiCH}_{3}\right)$ and $1083 \mathrm{~cm}^{-1}(\mathrm{vSiOSi})$, observed at the surface of the samples (Figure $3 \mathrm{a}$ ), were due to a polysiloxane-based contaminant used for mold releasing. After aging (Figure $3 b$ ), there was an intensification of these bands probably due to exudation of the absorbed contaminant.

Changes in the infrared spectra of 8-week aged samples analyzed at surface (Figure 3b) can be related to breakage of double bonds and to hydroxyl and carbonyl build-up. The breakage of double bonds was indicated through some loss of absorption of $\mathrm{CH}$ stretching bands (3100-2800 $\left.\mathrm{cm}^{-1}\right)$, meanwhile $\mathrm{CH}$ wag bands at 994 and $911 \mathrm{~cm}^{-1}$ $\left(\omega \mathrm{CH}\right.$ and $\omega \mathrm{CH}_{2}$ vinyl); $965 \mathrm{~cm}^{-1}$ ( $\omega \mathrm{CH}$ trans $)$ and $725 \mathrm{~cm}^{-1}(\omega \mathrm{CH}$ cis $)$ suffered a drastic reduction. Although the presence of the $\mathrm{vC}=\mathrm{O}$ band due to the urethane functional group significantly masks carbonyl build-up, the $\mathrm{C}=\mathrm{O}$ stretching region showed a higher absorption, slightly more intense for F1-formulation, and an enlargement of the overlapping twin bands related to free and hydrogen bonded $\mathrm{vC}=\mathrm{O}$ at 1725 and $1712 \mathrm{~cm}^{-1}$, respectively. In addition, an increase in $\mathrm{OH}$ stretching absorption between 3600 and $3200 \mathrm{~cm}^{-1}$, which was also more pronounced for F1-formulation, could be observed, and can be assigned to formation of alcohol or carboxylic acid groups. In fact, previous work ${ }^{2}$ have showed that products from polybutadiene oxidation are mostly comprised by alcohols.

All the alterations reported above were not observed for the samples analyzed at the cross-sectioned face (Figure 3c), thus indicating that the oxidative cross-linking of HTPB-binders is limited by oxygen diffusion, as previously reported by other authors ${ }^{11}$.

Infrared analysis of samples aged at $70{ }^{\circ} \mathrm{C}$ for periods of time longer than 8 weeks showed the same behavior as presented in Figure 3 (data not shown), with spectra alterations being noticed only in the external surface.

\section{Conclusions}

The presence of a higher number of urethane linkages promoted by a higher $\mathrm{NCO} / \mathrm{OH}$ ratio was found to accelerate the oxidation of HTPB/IPDI-based polyurethanes during thermal aging. Changes in chemical and mechanical properties have confirmed oxidative cross-linking as the main mechanism of HTPB-binder degradation.

\section{Acknowledgments}

Financial support from Agência Espacial Brasileira (AEB) is recognized. TC acknowledges $\mathrm{CNPq}$ for the undergraduate scholarship (PIBIC-IAE).

\section{References}

1. Davenas A. Development of modern solid propellants. Journal of Propulsion and Power. 2003; 19(6):1108-1128. http://dx.doi. org/10.2514/2.6947

2. Nagle DJ, Celina M, Llewellyn R and Fredericks PM. Infrared microspectroscopic study of the thermo-oxidative degradation of hydroxyl-terminated polybutadiene/isophorone diisocyanate polyurethane rubber. Polymer Degradation and Stability. 2007; 92(8):1446-1454. http://dx.doi.org/10.1016/j.polymdegradstab.2007.05.010

3. Akbas A, Aksoy S and Hasirci N. Effects of thermal ageing on the properties and lifetime prediction of hydroxyl-terminated polybutadiene. Polymer. 1994; 35(12):2568-2572. http://dx.doi.org/10.1016/00323861(94)90380-8

4. Dubois $\mathrm{C}$ and Perreault F. Shelf life prediction of propellants using a reaction severity index. Propellants, Explosives, Pyrotechnics. 2002, 27(5):253-261. http://dx.doi.org/10.1002/1521-4087(200211)27:5\%3C253::AID-PREP 253\%3E3.0.CO;2-8

5. Haska SB, Bayramli E, Pekel F and Ozkar S. Mechanical properties of HTPB-IPDI-based elastomers. Journal of Polymer Science. 1997; 64(12):2347-2354.

6. Manjari R, Joseph VC, Pandureng LP and Sriram T. Structure-property relationship of HTPB-based propellants. I. Effect of hydroxyl value of HTPB resin. Journal of Applied Polymer Science. 1993; 48(2):271-278. http://dx.doi.org/10.1002/app.1993.070480211

7. Hocaoglu O, Ozbelge T, Pekel F and Ozkar S. Aging of HTPB/APbased solid propellants, depending on the $\mathrm{NCO} / \mathrm{OH}$ and triol/diol ratios. Journal of Applied Polymer Science. 2001; 79(6):959-964. http://dx.doi.org/10.1002/1097-4628(20010207)79:6\%3C959::AID-AP P10\%3E3.0.CO;2-G

8. Eroglu MS. Characterization of the network structure of hydroxyl terminated poly(butadiene) elastomers prepared by different reactive systems. Journal of Applied Polymer Science. 1998; 70(6):1129-1135. http:// dx.doi.org/10.1002/(SICI)1097-4628(19981107)70:6\%3C1129::AID-AP P9\%3E3.0.CO;2-Q

9. Christiansen AG, Layton LH and Carpenter RL. HTPB propellant aging. Journal of Spacecraft and Rockets. 1981; 18(3):211-215. http://dx.doi. org/10.2514/3.57807

10. Chattopadhyay DK and Webster DC. Thermal stability and flame retardancy of polyurethanes. Progress in Polymer Science. 2009; 34(10):1068-1133. http://dx.doi.org/10.1016/j.progpolymsci.2009.06.002

11. Ahlblad G, Reitberger T, Terselius B and Slenberg B. Thermal oxidation of hydroxyl-terminated polybutadiene rubber. II, Oxidation depth profiles studied by imaging chemiluminescence. Polymer Degradation and Stability. 1999; 65(2):185-191. http://dx.doi.org/10.1016/S01413910(98)00178-5 